\title{
Peer feedback: moving from assessment of learning to assessment for learning
}

\section{Sigrun M. Wagner}

School of Management, Royal Holloway, University of London, UK

\section{Abstract}

The following case study showcases a model of academic peer learning that has demonstrated clear links to learning development in final year students. The paper discusses the introduction of a new assessment structure for a 15 credit course unit usually taken by 90 students in the form of a short discursive essay (500 words) due early in the first teaching term. This essay is peer assessed in groups of four students. The peer feedback and tutor mark then serve as formative feedback (feed forward) for the main, longer essay (2-2,500 words) due in the second teaching term. Following the outline of the case background, details of the peer assessment are provided, including its development and structure. The new assessment structure has resulted in deeper learning, positive student feedback, fewer student complaints with regard to grades received for the main essay, and better preparation for the final exam. Reflections are offered in the conclusion.

Keywords: peer assessment; assessment for learning; peer learning; peer feedback.

\section{Introduction}

In recent years, increased attention has been paid to the use of peer-assisted learning in higher education (van den Berg et al., 2006; Lladó et al., 2014). Its importance was, for example, highlighted by the Chief Executive of the UK's Higher Education Academy during a visit to the author's institution in 2014.

The course for which peer assessment was pioneered is a 15 credit unit run over one term in the International Business subject area for final year students in the institution's School 
of Management. It is an optional course for BSc Management students and compulsory for students studying for a BSc Management with International Business. Until the author's introduction of it, peer feedback had rarely been used in the School. The following table gives an overview of the assessment before and after the introduction of peer assessment.

Table 1. Comparison of assessment structures.

\begin{tabular}{|c|c|}
\hline Previous assessment structure & New assessment structure \\
\hline $\begin{array}{l}\text { - } 30 \% \text { Coursework essay }-2,500 \\
\text { words, due in the final week of term } \\
1 \text { (November/December). }\end{array}$ & $\begin{array}{l}\text { - } 10 \% \text { Discursive essay - } 500 \text { words, } \\
\text { due after the third week of term } 1 \\
\text { (October). } \\
\text { - } 5 \% \text { Verbal participation in } \\
\text { workshops and lectures } \\
\text { - } 25 \% \text { Coursework essay }-2,000- \\
2,500 \text { word essay, due at start of } \\
\text { term } 2 \text { (January). } \\
60 \% \text { Written examination, } 2 \text { hours } \\
\text { (Summer term - term 3) }\end{array}$ \\
\hline
\end{tabular}

The piece of assessment used for peer feedback was a short 500 word discursive essay that students had to submit in the early part of term 1 (in week 4), worth $10 \%$ of the final course grade (a discursive essay in this context encourages students to engage with a discourse of a certain topic, taking into account various perspectives in the process).

Whilst the author, as lecturer and course coordinator, was still responsible for the numeric mark (summative feedback), students were responsible for providing online written (formative) feedback to each other in groups of four, facilitated by the virtual learning environment (Moodle). Students then had to use the feedback as feedforward for their main essay by 'reflecting and explaining' in a paragraph (outside the word count) how they acted on the peer feedback received. 


\section{Why did the assessment change?}

The rationale behind the change of assessment in introducing peer feedback was to move from assessment of learning to assessment for learning. Such learning-oriented assessment is one important goal of peer assessment (Gielen et al., 2011). The revised structure thus provides more opportunity for feedback and learning. It also constitutes a shift from a teacher-centred approach towards a more student-centred approach to learning (Entwistle et al., 2000), which is part of a wider movement to focus more on the student experience (BIS, 2011).

Taking a student-centred approach is a significant characteristic of good teaching (Bhatti, 2012). Furthermore, good practice in undergraduate education emphasises prompt feedback, and encourages and develops reciprocity and cooperation among students (Chickering and Gamson, 1987). The use of peer feedback also addresses the desire of students to develop peer relationships and to benefit from peer support (QAA NUS Student Experience Research Report, 2012). It thus builds student independence where students take responsibility for their own learning by actively managing it (Liu and Carless, 2006; Lladó et al., 2014) rather than solely relying on their tutor. The new assessment structure aimed to incorporate the principles and values outlined here.

Among these principles of effective assessment, transparency of criteria is key. This underpinned the exercise, therefore attempting to bridge the gap between student uncertainty and expectations of lecturers (Magyar et al., 2011). The students were able to gain greater insight into what was required of them in order to meet the assessment criteria. Well ahead of the main essay they actively engaged with the criteria in order to give valid and useful feedback to their peers. Dochy et al. (1999) point out the importance of clear marking criteria, while Jones and Alcock (2014) provide an alternative view where no criteria are provided in a piece of peer assessment. See also, for example, the work of ASKe at Oxford Brookes University for engaging students with assessment criteria (https://www.brookes.ac.uk/aske/documents/2576 123-Improve90Mins.pdf, Assessment Standards Knowledge exchange, accessed 11 November 2015, based on Rust et al., 2003).

The introduction of a second essay with peer feedback on the course contributes to the development of writing skills (Bowman and Addyman, 2014). Furthermore, peer feedback 
also actively strengthens employability skills as it is used in work contexts as well (Lladó et al., 2014): professionals are subject to criticism by others of the same rank and, as responsible employees, are expected to judge fairly other peers' work (Lladó et al., 2014).

\section{How was the new assessment structure introduced?}

The author as the course coordinator and assessor introduced peer feedback in consultation with the university's Educational Development department. The change was prompted partly as a result of a previous piece of pedagogical research on good practice in teaching conducted by the author, and partly as a result of experiencing student questions, complaints and queries following the release of coursework marks within the original assessment structure.

In discussions with the educational development officers, the assessment took shape and it was decided to introduce peer feedback as a formative element and to make the lecturer responsible for the summative element (numerical mark). It was important for students to give only online written, formative feedback and for the tutor to give summative marks. Some students dislike awarding a grade to their peers (Falchikov, 1995) whilst others do not have confidence in peer assessors (Swanson et al., 1997). Topping (1998) and Hughes (2001), however, present evidence that indicates that peer assessment can be effective, although students tend to mark more generously than academics (Ferguson et al., 2008).

Whilst providing quantitative assessment in the form of a numerical mark might place peers in too much of a teacher-like role, giving formative and qualitative feedback is also more cognitively demanding (Topping, 2005) and thus more appropriate and suitable for learning development. Scardamalia (2001) emphasises such higher order skills as characteristic twenty-first century skills in modern education (van Zundert et al., 2012). Furthermore, receiving feedback from more than one peer is more useful than feedback from a single peer or tutor (Luxton-Reilly, 2009; Cho and Schunn, 2007).

The following timeline gives an overview of the assessment and feedback process. A similar table was also given to students on the course. 
Table 1. Time line of peer assessment in case study course.

\begin{tabular}{|c|c|}
\hline Term 1 & Activity \\
\hline Week 2 & $\begin{array}{l}\text { - Explanation in lecture of the assignment and peer feedback } \\
\text { process } \\
\text { - Homework - assessment exercise with } 3 \text { model essay extracts } \\
\text { (made available on Moodle) } \\
\text { - Assignment of peer feedback groups (groups of four) }\end{array}$ \\
\hline Week 3 & - Assessment exercise in class \\
\hline Week 4 & $\begin{array}{l}\text { - Deadline for essay submission on Turnitln and to peer feedback } \\
\text { group via Moodle forum }\end{array}$ \\
\hline Week 5 & $\begin{array}{l}\text { - Essays are read and peer reviewed by three other group members } \\
\text { (every student peer reviews three essays and receives feedback } \\
\text { from three fellow students) }\end{array}$ \\
\hline Week 6 & $\begin{array}{l}\text { - Deadline for peer feedback submission to peer group and to tutor } \\
\text { via Moodle forum } \\
\text { - Tutor starts grading }\end{array}$ \\
\hline Week 8/9 & - Tutor returns graded essays \\
\hline \multicolumn{2}{|l|}{ Term 2} \\
\hline Week 1 & $\begin{array}{l}\text { - Main essay due with reflective paragraph (outside word count) on } \\
\text { how student acted on feedback given for discursive essay ( } \rightarrow \\
\text { feedforward) }\end{array}$ \\
\hline
\end{tabular}

In order to prepare students for the provision of peer feedback, an assessment exercise in the form of three essay extracts was devised, in line with Luxton-Reilly's (2009) emphasis on the use of exemplars to help students identify the merits of a given assignment. The extracts demonstrated the quality (and the limitations) of each piece according to the marking/feedback criteria. The following list gives an overview of the peer feedback checklist that was given to students for the assessment exercise and for the peer assessed discursive essay:

- Has your peer used and listed at least seven sources, two of which should be from academic journals, two from news sources (e.g. FT, Economist, other broadsheets etc.) and at least one textbook source, one digital media source (e.g. blog, tweet) and one public speech? 
- Are the references used effectively (e.g. not just quotations but is there interpretation as well)? Is the referencing consistent? - i.e. are all references listed used and are all references used listed? Are the references written up correctly, by surname/organisation?

- Is the essay well written? Has it been proofread or was it possibly submitted in haste? Are all words written out in full, i.e. by not using contractions (e.g. 'is not' rather than 'isn't')? Are all abbreviations explained when first used? Is the formatting consistent (e.g. colour, font type, font size, line spacing...)? Is the word count stated?

- Has your peer answered the question?

- List three recommendations how the essay could be improved.

- You should also use the assessment grid for undergraduate essays to guide your feedback and to make comments in the following areas: intellectual qualities expressed, structure and organisation, level of reading, quality of referencing, and writing style.

In addition to the checklist, students were provided with clear rules for feedback: it should be constructive and positive, whilst also aiming to be honest and balanced. They were reminded in the instructions that 'giving feedback is an important skill in the workplace where you might be asked to appraise peers, line managers or subordinates; it is a tool for development and improvement', thereby clearly stressing the developmental aspects of this kind of learning activity. All students had to answer the same essay topic and as the nature of the question allowed for wide interpretation with no right or wrong answers, model answers were not provided, encouraging students to develop critical thinking skills. The checklist and rules for feedback were judged to provide sufficient material for the students to work with.

Feedback groups of four were assigned randomly across the course of 90 students in the first year of the intervention. Following student feedback about not knowing whom they were peer assessing (the students are part of a larger cohort of over 350 management students who might not all know each other), students were assigned randomly within the four workshops of the course (each attended by 20-25 students) in the second year of the new assessment structure. This ensured a higher likelihood of students knowing their assessors and assessees. 
The timing of the essay and the feedback guaranteed that students ended the taught part of the course having received feedback and a grade. This marked a change from the previous assessment structure where they only handed in their coursework towards the end of the course and did not receive feedback until the following term.

In a further step, as part of the main essay assessment due four weeks after the end of term one, students had to reflect on the feedback they had received on their discursive essay. The peer assessment thus acts as feedforward for self-reflection and selfevaluation, thereby enhancing students' meta-cognitive competencies (Topping, 2005; Dochy et al., 1999; see also Reinholz, 2016 on the relationship between peer and selfassessment; for more information on how feed forward can be used to look ahead to the next assignment, see Ferrell and Gray's (2013) guide to feedback and feed forward, https://www.jisc.ac.uk/guides/feedback-and-feed-forward, accessed 8 September 2015). Peer feedback also improved their writing skills as supported by the scaffolding process introduced (Yang, 2010). The importance of feedback is emphasised by Orsmond et al. (2004, p.274): 'fundamental to a formative learning process is the use of feedback'.

\section{Outcomes of the assessment change}

For the tutor, the overall workload has been marginally higher - e.g. overall the coursework word count to mark has gone from 2,500 to a range of 2,500-3,000 words. Marking time for the discursive essay is minimal compared to other assignments as online written feedback is provided by students rather than by the tutor who provides a numerical mark, and because all students have the same essay assignment. Furthermore, following the release of marks for the main essay, there have been fewer questions and queries (or complaints) from students: a significant improvement to the previous assessment structure.

For the students, clear learning developments have been demonstrated. The evidence can be seen in several ways. In both years, all students registered on the course submitted a discursive essay (non-submission would result in a mark of $0 \%$ ), whereas not all students submitted the longer essay, indicating a very high level of student engagement for the peer assessed essay. In the first year of the new assessment structure, a post-it-note exercise (similar to one of the classroom assessment techniques advocated by Angelo 
and Cross, 1993) was conducted, shortly after the marks had been released. Students were asked whether they had engaged in peer assessment before, how they found the exercise, whether it should be repeated and how it could be improved. More than $80 \%$ of the students surveyed ( $\mathrm{N}=36$ out of a cohort of 90 students, i.e. over a third of registered students - this level of attendance and engagement is common for lectures during this part of the course where workshops are attended more fully) were positive about the peer feedback, finding it useful, helpful, and informative. Students clearly appreciated the reciprocal benefits for them from both reading other students' essays and receiving feedback from their peers. This was also evident in the general student feedback for the course, of which two extracts read as follows:

- The peer assessment feedback process was a fun, useful exercise - was good to hear what other students thought.

- Two essays to write is really good, raises awareness of the course from October onwards.

Similarly, the benefits as perceived by students were demonstrated in the main essay. Students were asked to provide an additional paragraph (outside the word count) to 'reflect and explain' how they acted on the feedback given for the discursive essay, using it as feedforward. The following quotations are a selection from these paragraphs of reflection:

- The peer assessment that we had in our first essay was very helpful to me... This activity is indeed very helpful for students as opinions for [sic] different people with different perspectives truly matters.

- I found the assessment exercise more useful when assessing than when being assessed... As both assessee and assessor, it made me realise how many mistakes, confusions, or even imprecisions we constantly leave in our essays. So when quoting my sources this time I kept asking myself whether what I was saying was really what the source said, or whether I was making it up. It also drew my attention on points that I formerly found less relevant, such as the layout which actually determines whether the essay is pleasant to read or not.

- The peer assessment was very useful to me because it showed me different ways of approaching the question and I was able to learn from other students' mistakes. I also find that getting feedback from your peers is different than comments of tutors 
and it showed me more clearly how we get assessed. All in all I thought it was very successful and in my eyes it is a useful tool and would recommend other tutors use this technique as well.

- ... Moreover, when I was correcting my peer's work I was put in the position of the professor who marks the work, therefore, I was able to gain an insight into what you expect from an essay and how the written information is perceived by that person.

The last quotation points to a development of empathy with lecturers which is also a theme that Hanrahan and Isaacs (2001) found in their study of how students view peer assessment. Interestingly, weaker essays often did not include the reflective paragraph, reinforcing the notion that reflecting on peer feedback leads to improvements in writing.

In terms of numerical marks, the average grade of the second essay for the 90 students on the course increased by $1.5 \%$ percentage points from $58.0 \%$ for the first essay to $59.5 \%$ in the first year of the changed assessment, with a significant $45 \%$ increase in students gaining a first class mark (from 11 students to 16, with stable student numbers overall). In the higher education context for undergraduate students in England, a first class mark is obtained with a grade above $70 \%$. A pass mark is above $40 \%$ (third class), whereas grades above $50 \%$ and $60 \%$ constitute second class marks (lower and upper second). Marks above $85 \%$ or $90 \%$ are rare in the social sciences. Exam results in the two years since introducing the peer assessment have both been higher by two to three percentage points compared to the final year of the previous assessment structure. Furthermore, in both years, exam results have been higher than essay results which also marks a shift from the previous assessment structure, indicating the development of learning from the two essays to the examination. As there are other factors influencing grades, numeric marks can of course only serve as an indicator of the benefits to students' learning development by introducing peer assessment. Ferguson et al. (2008) for example highlight the varied reliability of marking, drawing on Newstead and Dennis (1994), as well as Falchikov and Boud (1989), emphasising the difficulties of marking essay-style assessments in the social sciences.

Whilst a couple of students reported back that 'the only feedback that counts is the tutor's' (see also Liu and Carless, 2006, for similar concerns), perhaps indicating a lack of reflection, most students valued the experience. Although other studies debate rewarding the quality of feedback (Davies, 2009), the feedback given was not marked itself. 
However, the names of students who had given particularly constructive and/or detailed feedback in line with the checklist were read out in class as an informal reward. For future cohorts, these written online comments could be used as anonymous examples of effective feedback practices, provided students have given permission to use their comments as resources for incoming students.

The engagement of students with peer feedback is also demonstrated in the fact that the peer assessment forum is the most accessed feature on the Moodle site of the course along with the instructions for the peer assessed discursive essay. Timely feedback had been an issue previously on the course and in the School more widely. The introduction of an early piece of coursework with peer feedback has not only led to enhanced student learning but also contributed to improved scores on 'Assessment \& Feedback' for this unit in the anonymous student feedback surveyed at the end of each taught course.

\section{Concluding reflections}

In the student feedback on the peer assessment, several students commented that they would have liked to have anonymous feedback as they did not like giving feedback to their friends. At the same time, as referred to above, some students disliked giving and receiving feedback to and from students whom they did not know. Although anonymous feedback could lead to more honest feedback in that assessors might be less critical when identities are known (Cho and Schunn, 2007; Cramton, 2001), the rationale for known identities was two-fold: practical reasons (the university's virtual learning environment does not currently support such peer assessment) and developmental reasons. In the workplace, feedback and appraisal are rarely anonymous, and as such, giving nonanonymous feedback to peers may prepare students for employment by practising an important professional skill (van Zundert et al., 2012; Lladó et al., 2014). Anonymous marking is more appropriate in contexts where peer assessment also includes grading rather than only giving feedback (see Luxton-Reilly, 2009, as well as Yu and Wu, 2011, for a discussion on identity revelation in peer assessment). For reasons discussed above, the tutor provided the numerical mark as the summative element, and students the written feedback as formative assessment. 
In the first two years of the new assessment structure, the tutor did provide some online written feedback to students in addition to a numerical mark, in anticipation of some students not providing feedback. In the first year this was more widespread and in the second year, measures were taken to penalise students not providing feedback by deducting 5\% percentage points from their mark - this affected two out of 90 students. In future, the tutor plans to revert to the original plan and only give a numerical mark, whilst at the same time offering verbal feedback to students who (feel they) have not received sufficient peer feedback, once the grades have been released, thus contributing to student independence to manage their own learning (Lladó et al., 2014). Furthermore, the somewhat unwieldy checklist for peer feedback has been changed and restructured, e.g. by including subheadings, for more clarity.

The innovative nature within the author's institution of the introduction of this peer assessment was recognised by the award of a university-wide teaching prize to the tutor. The case study was shared as good practice in the institution's annual Teaching and Learning Symposium in 2015 under the theme 'Valuing Teaching and Sharing Approaches'. The comments and questions raised as a result of sharing good practice in this forum provided further opportunities for reflection on how to enhance learning and empower learners through peer assessment.

\section{Acknowledgments}

The author would like to acknowledge the generous help and advice of the team in Educational Development, particularly Lynne Francis, with regard to peer assessment, its preparation, implementation and technical support, all of which is much appreciated.

\section{References}

Angelo, T.A. and Cross, K.P. (1993) Classroom assessment techniques: a handbook for college teachers. $2^{\text {nd }}$ Edn. San Francisco: Jossey-Bass. 
Bhatti, M.T. (2012) 'Dimensions of good university teaching: faculty and department chairs' perspectives', Design and Technology Education: An International Journal, 17(1), pp. 44-53.

BIS (2011) Higher Education: Students at the Heart of the System, Department for Business Innovation and Skills (BIS) White Paper, June. Available at: https://www.gov.uk/government/uploads/system/uploads/attachment data/file/3138 4/11-944-higher-education-students-at-heart-of-system.pdf (Accessed: 26 May 2015).

Bowman, M. and Addyman, B. (2014) 'Improving the quality of academic reflective writing in nursing: a comparison of three different interventions', Journal of Learning Development in Higher Education, Issue 7, June, pp. 1-25.

Chickering, A.W. and Gamson, Z.F. (1987) 'Seven principles for good practice in undergraduate education', AAHE (American Association for Higher Education) Bulletin, March, pp. 3-7.

Cho, K. and Schunn, C.D. (2007) 'Scaffolded writing and rewriting in the discipline: a webbased reciprocal peer review system', Computers \& Education, 48(3), pp. 409-426.

Cramton, C.D. (2001) 'The mutual knowledge problem and its consequences for dispersed collaboration', Organization Science, 12(3), pp. 346-371.

Davies, P. (2009) 'Review and reward within the computerised peer-assessment of essays', Assessment \& Evaluation in Higher Education, 34(3), pp. 321-333.

Dochy F., Segers, M. and Sluijsmans, D. (1999) 'The use of self-, peer and co-assessment in higher education: a review', Studies in Higher Education, 24(3), pp. 331-350.

Entwistle, N., Skinner, D., Entwistle, D. and Orr, S. (2000) 'Conceptions and beliefs about 'good teaching': an integration of contrasting research areas', Higher Education Research \& Development, 19(1), pp. 5-26. 
Falchikov, N. (1995) 'Peer feedback marking: developing peer assessment', Innovations in Education \& Training International, 32(2), pp. 175-187.

Falchikov, N. and Boud, D. (1989) 'Student self-assessment in higher education: a metaanalysis', Review of Educational Research, 59(4), pp. 395-430.

Ferguson, G., Sheader, E. and Grady, R. (2008) 'Computer-assisted and peer assessment: a combined approach to assessing first year laboratory practical classes for large numbers of students', Bioscience Education, 11(1), pp. 1-16 [Online]. Available at: http://www.tandfonline.com/doi/full/10.3108/beej.11.4 (Accessed: 12 April 2016).

Ferrell, G. and Gray, L. (2013) Feedback and feed forward, guide. Available at: https://www.jisc.ac.uk/guides/feedback-and-feed-forward (Accessed: 8 September 2015).

Gielen, S., Dochy, F., Onghena, P., Struyven, K. and Smeets, S. (2011) 'Goals of peer assessment and their associated quality concepts', Studies in Higher Education, 36(6), pp. 719-735.

Hanrahan, S.J. and Isaacs, G. (2001) 'Assessing self- and peer-assessment: the students' views', Higher Education Research \& Development, 20(10), pp. 53-70.

Hughes, I. (2001) 'But isn't this what you're paid for? The pros and cons of peer- and selfassessment', Planet, National Subject Centre for Geography, Earth and Environmental Sciences, Learning and Teaching Support Network, Issue 2, pp. 2023.

Jones, I. and Alcock, L. (2014) 'Peer assessment without assessment criteria', Studies in Higher Education, 39(10), pp. 1774-1787.

Liu, N-F. and Carless, D. (2006) 'Peer feedback: the learning element of peer assessment', Teaching in Higher Education, 11(3), pp. 279-290. 
Lladó, A.P., Soley, L.F., Sansbelló, R.M.F, Pujolras, G.A., Planella, J.P., Roura-Pascual, N., Suñol, J.J. and Moreno, L.M. (2014) 'Student perceptions of peer assessment: an interdisciplinary study', Assessment \& Evaluation in Higher Education, 39(5), pp. 592-610.

Luxton-Reilly, A. (2009) 'A systematic review of tools that support peer assessment', Computer Science Education, 19(4), pp. 209-232.

Magyar, A., McAvoy, D. and Forstner, K. (2011) "If only we knew what they wanted': bridging the gap between student uncertainty and lecturers' expectations', Journal of Learning Development in Higher Education, Issue 3, March, pp. 1-18.

Newstead, S.E. and Dennis, I. (1994) 'Examiners examined: the reliability of exam marking in psychology', The Psychologist, 7(5), pp. 216-219.

Orsmond, P., Merry, S. and Callaghan, A. (2004) 'Implementation of a formative assessment model incorporating peer and self-assessment', Innovations in Education and Teaching, 41(3), pp. 273-290.

QAA NUS Student Experience Research Report (2012) Quality Assurance Agency for Higher Education, National Union of Students, report. Available at: http://www.qaa.ac.uk/publications/information-andguidance/publication?PubID=225\#.VwVggOI1jlU (Accessed: 6 April 2016).

Reinholz, D. (2016) 'The assessment cycle: a model for learning through peer assessment', Assessment \& Evaluation in Higher Education, 41(2), pp. 301-315.

Rust, C., Price, M. and O'Donovan, B. (2003) 'Improving students' learning by developing their understanding of assessment criteria and processes', Assessment and Evaluation in Higher Education, 28(2), pp. 147-164.

Scardamalia, M. (2001) 'Big change questions: will educational institutions, within their present structures, be able to adapt sufficiently to meet the needs of the information age?', Journal of Educational Change, 2(2), pp. 171-176. 
Swanson, D.B., Case, S.M. and van der Vleuten, C.P.M. (1997) 'Strategies for student assessment', Boud, D. and Felettti, G. (eds.) The challenge of problem-based learning. $2^{\text {nd }}$ ed. London: Kogan Page, pp. 269-282.

Topping, K.J. (1998) 'Peer assessment between students in colleges and universities', Review of Educational Research, 68(3), pp. 249-276.

Topping, K.J. (2005) 'Trends in peer learning', Educational Psychology: An International Journal of Experimental Educational Psychology, 25(6), pp. 631-345.

van den Berg, I., Admirall, W. and Pilot, A. (2006) 'Design principles and outcomes of peer assessment in higher education', Studies in Higher Education, 31(3), pp. 341-356.

van Zundert, M.J., Sluijsmans, D.M.A., Könings, K.D. and van Merriënboer, J.J.G. (2012) 'The differential effects of task complexity on domain-specific and peer assessment skills', Educational Psychology, 32(1), pp. 127-145.

Yang, Y-F. (2010) 'Students' reflection on online self-correction and peer review to improve writing', Computers \& Education, 55(3), pp. 1202-1210.

Yu, F.Y. and Wu, C.P. (2011) 'Different identity revelation modes in an online peerassessment learning environment: effects on perceptions toward assessors, classroom climate and learning activities', Computers \& Education, 57(3), pp. 2167 2177.

\section{Author details}

Dr Sigrun M. Wagner is a Senior Lecturer in International Business and Sustainability in the School of Management at Royal Holloway, University of London, UK. Following her undergraduate degree in European Studies at the University of Osnabrück in Germany, she moved to Loughborough University, UK, for her postgraduate degrees in International Management and research in Corporate Political Activities before joining Royal Holloway in 2009. She has won teaching prizes and is interested in using peer assessment, as well as games and simulations, to stimulate student learning. 